\title{
English Boxing between Corporeality and Socialization of Gafsa ISSEP Students
}

\author{
Tesnime Hamdi' ${ }^{1}$ Faiza Ayed ${ }^{2}$, Bassem Hidouri ${ }^{3}$, Zouhaier Ben Jannet ${ }^{4}$, Ali Elloumi ${ }^{4}$ \\ ${ }^{1}$ ISSEP Gafsa, Tunisia \\ ${ }^{2}$ ISSEP Ksar Said, Tunisia \\ ${ }^{3}$ ISEAH Gafsa, Tunisia \\ ${ }^{4}$ FLSH Sfax, Tunisia \\ Email: tassou.hamdi@yahoo.fr, faizaayed89@yahoo.fr, hid.teacher@yahoo.fr, benjannet2004@gmail.com, alielloumi62@gmail.com
}

How to cite this paper: Hamdi, T., Ayed, F., Hidouri, B., Jannet, Z. B., \& Elloumi, A. (2019). English Boxing between Corporeality and Socialization of Gafsa ISSEP Students. Advances in Applied Sociology, 9, 446-461.

https://doi.org/10.4236/aasoci.2019.99033

Received: July 30, 2019

Accepted: September 15, 2019

Published: September 18, 2019

Copyright $\odot 2019$ by author(s) and Scientific Research Publishing Inc. This work is licensed under the Creative Commons Attribution International License (CC BY 4.0).

http://creativecommons.org/licenses/by/4.0/

\begin{abstract}
We tried to highlight the influence of the socialization modes on the construction of different relationships with the body from a body of interviews. To collect relevant data, our study is based on a qualitative approach. At Gafsa Higher Institute of Sport and Physical Education, we chose to proceed by means of semi-directed interview with students who practice English Boxing. In fact, individuals are not subject to the same socialization mode regarding that personal characteristics are specific. In other words, individuals do not receive the same standards and values and that's why we talk about a gendered socialization within sports disciplines. Our major concern is to check the applicability of our theoretical model on the relationship between socialization and corporeality on English boxing.
\end{abstract}

\section{Keywords}

Corporeality, Corps Sociology, Socialization, Body Socialization, English Boxing, Sex

\section{Introduction}

Being an integral part of sociology, the body sociology aims to study the human body representations within social issues. The body is what connects an individual to his social environment. This means that an individual seeks to construct and to adapt certain bodily characteristics and behaviors to match them with expected social characteristics and behaviors related to the individual biological sex.

We have to know that corporeality field involves knowledge related to life 
sciences (anatomy, physiology, etc.) and knowledge related to the human sciences (philosophy, sociology, semiology, etc.). Thus, it is undeniable that the physical fact complex nature mobilizes a network of variable meanings that urge to refer to a multitude of explanatory paradigms in order to highlight its various dimensions. In this perspective, it is necessary to refer more comprehensively to the body phenomenological dimension in the way it allows to emphasize the body different existential modalities. Based on this conception, corporeality is perceived as "the constant habitat of the subject and the sum of the lived experiences that translate the body concrete existence in the world" (Merleau-Ponty, 1996: p. 106). Thus, the body is first and foremost an organic reality subject to objective laws. On the one hand, it is the "body-in-itself" grasped in its different aspects and conceived as a physical body as apprehended in the scientific logic determinism. On the other hand, the "body-for-itself" is the proper body on which subjectivity is based. Therefore, the proper body refers to all the lived reality that summarizes individual's experiences. The last bodily modality existence is manifested in the "body-for-others" which, through inter-subjectivity, attributes meaning to social reality and materializes the subject's relationship with others (Henry, 2001: p. 207).

For Christine Détrez (2002: pp. 220-236), "the body is a nature gift (more or less graceful)". This is translated in the fact that the individual develops in a particular body through all the life stages. Any changes, including makeup, hair color, transplants, sex change etc. cannot remove the body starting materials given at birth. This same nature determines the characters, the social positions, and the relation of cause and effect. It justifies the established order, legitimizes in a way the social order by postulating "that the biological characters of man make his position as a whole the one that comes to him in all justice." "Instead of making corporality an effect of the social condition of man, this thought makes the social condition the direct product of his body [...]. The destiny of man is inscribed from the outset in his morphological conformation (...). Finally, the world order obeys a biological order from which it is sufficient to look for evidence in the body appearances" (Le Breton, 1992: p. 16). On the one hand, the bodily self implies systematically the subject sex. On the other hand, it reinforces the conviction that the sexual dimorphism is universal. The subject in question cannot be confused with a global body figure, absolute and asexual. Given this representation, the categories "man" and "woman" are "two singularities specified by belonging sexes combined in the movement of existence by being similar, opposite and complementary" (Devereux, 1998: pp. 335-367). Therefore, it seems clear that the body plays the role of the factor of distinction since it is provided with a power drawn from its capacity to ignore the ambiguities to which it gives rise. It is the initial and principal element of an individual identity. It is a vital link in the process of self-definition. It is closely related to a social dimension determined by the eyes of others, their judgments and their appreciation. This dynamic of the individual and the collective can develop in a culture while keeping its values and codes that take shape in an identity includ- 
ing a gender identity resulting from a whole process of constructing the differences between the "men" and "woman" categories. It is precisely cultural intelligibility norms that determine the gender that will in turn specify masculinity and femininity whose signs appear on the body and reveal it as an "incarnated garment". Thus, gender is attributed to arbitrariness which is a kind of integrated law that manifests itself "on the surface of bodies, the same ones that it produces" (Butler, 2006: p. 257). In short, corporeality is apprehended in a masculine or in feminine subjectivity that identifies itself with a cultural belonging and adopted social meaning. Femininity and masculinity are emphasized in corporeality through distinctive bodily forms, gestures and different body uses. Merging into the bodily self, these properties compel the individual and the bodily appearance to wall up in behavioral patterns that correspond to the sex of belonging. Femininity and masculinity are highlighted by the differentiated criteria determining them through outlines of models of the female body and the male body. Essentially social product, this production commits us to admit its necessity and its naturalness (Butler, 2006: p. 264), and its apparently immutable appearance. In addition, Socialization implies a relationship to the body specific to each individual seeking to put it in "social conformity". In this perspective, the study of the body arouses an undeniable interest as it relates to the innate dimensions and the acquired body characteristics. Therefore, the experience of the body is apprehended according to the requirements of the activity in which it is invested (football, boxing and aerobics). In this sense, "corporeality is considered as a discursive operator" (Berthelot, 1992: p. 11). It represents a solution to understand the social systems functioning and mainly the sports system and its relation to the gender issue. The practice of sport remains a socialization proven factor that is, by its internal logic, influenced indirectly by each socio-motor activity.

Socialization is a continuous process because the individual is continually subject to change in the social context. There is no doubt that all the life periods are valid in this process especially the early childhood during which the vital first educations are acquired. More than any other, the socialization of gender is certainly the first of the socializations. It remains marked by an immediate reference to people sexual nature and physical rooting. In this context, Françoise Héritier says "only female bodies make children of both sexes" (1996: pp. 172-175). Admittedly, high-level sports practice requires a body whose potential transcends cultural differences especially those related to genre prescriptions. High competition sport has specific criteria in terms of its form, its techniques, its implied rules, and the body uses. In fact, the various sports techniques "constitute a model of universal and undifferentiated practice for all social groups, for all age categories and categories of sex" (Arnaud, 1996: pp. 147-183). From this perspective, sport has the particularity of introducing a model of unisex exercise involving a similar relationship between the two sexes in their investment modes. In this context, Lachheb (2008b: pp. 57-74) emphasizes that "for both sexes, the body uses are codified and legitimized by reference to a body model, the sport- 
ing body which stands out prescriptive values and specific body norms". If all the sports body criteria converge towards a model of physical strength, performance and competitiveness closely linked to masculine norms, masculinity is defined as a hegemonic reference in the sports field and we cannot completely deny the practice aspect (Bryson, 1990: pp. 97-99). In a certain way, this makes us think of the body as an asexual entity.

In this research context, Lachheb, M. (2013: pp. 445-463) is conducting a study on the socialization processes of high-level Tunisian footballers. The work focuses on the socialization process of Tunisian women athletes practicing high-level football and it specifically targets the construction process of the so-called masculine provisions. In another study Lachheb, M. (2008a: pp. 57-74) tries to apprehend the physical experience of Tunisian women who have integrated the practice of high-level judo. The study highlights the characteristics of the body experience of these Tunisian women who have integrated a sport traditionally recognized as masculine. From another perspective, Mennesson, C. (2005: p. 365) undertakes a substantial fieldwork that has been spread over a period of five years. The study focused on women's involvement in three predominantly male sports, namely football, boxing and weightlifting. This ethnographic survey focused on a more or less participatory observation that brings together discourses and practices. The sociologist focuses on the social conditions that determine to a certain extent the "choice" of practices considered the prerogative of men and the effects of prolonged socialization in a "masculine" universe. In fact, this comparative study of three sports activities that are not very integrated by women distinguishes this work of analysis of the construction of genres in the field of physical and sports activities.

The survey conducted by Jennifer Wesely (2001: pp. 162-180) on the social perception of the body of bodybuilders of both sexes has contributed in an efficient way to show the weight and the impact that these stereotypes may have in the social universe. To carry out his study of the natural-artificial continuum, Wesely relied on a series of six in-depth interviews and her own involvement for ten years in a gymnasium. She was able to demonstrate that extreme bodybuilding is presented as natural in men but artificial in women, because the body calls for a reconsideration of dominant expectations. Also, one cannot deny the stopping point beyond which androgyny is rejected and where the body-builder woman is confused with the man in the eyes of others. Performers and spectators are attentive to this limit and try to some extent to overcome it by the use of steroids more tolerated for men than for women. These are, in fact, called in these situations to consider their gender identity on the natural-artificial continuum.

Then, the masculine specifics of the physical being become the reference norms for sportswomen. Our goal is to study the relationship between socialization and corporeality within a socio-motor activity, namely English Boxing.

\section{Materials and Methods}

There is no doubt that socialization occupies a special place in sociology. It helps 
to understand many social phenomena. Nevertheless, this key concept is rarely highlighted in its relation to the body problematic. Yet, the body provides a decisive support for socialization process. Indeed, socialization by the body is rather differential. In the context of sports activities, it depends on the genre. It should be noted that the relationship between socialization and corporeality observed in sports is influenced by endogenous and exogenous factors.

In reality, Tunisian society is an extremely corporatized society. The body and the related issues (the body, body-centered, body-oriented sayings) dominate the whole Tunisian imagination. Moreover, body language relies on the body and corporeality to be more relevant.

All social or cultural changes have had as their point of attachment the body and corporeality. Indeed, the social transformations brought about by French colonization and the culture it developed in Tunisia gave the body and corporeality the power to drive social change. That said, the colonizer had put a lot of emphasis on the bodily appearance and had for that privileged, not to say imposed, the Western dress and prohibited traditional Tunisian clothing in the administrative institutions.

However, Tunisian society has worked to recover its culture in corporal manifestations and corporality. Through its transversality, the body has become an important study subject for several disciplines and sciences. Louvain-La Neuve sheds light on the arduous task of creating body sociology. For him, sociology should be focused on corporeality defined as "the set of phenomenal manifestations of bodily existence (...).” (Berthelot, 1983: pp. 119-132). In this perspective, the study of the body arouses an undeniable interest. It relates to the innate dimensions and the acquired male and female body characteristics.

The practice of sport remains a socialization proven factor. Each sport indirectly influences this socialization by its internal logic. Manifested in communication, interaction allows this socialization to materialize.

In order to highlight the relationship between socialization and corporeality in our research, we have chosen to make the following hypotheses:

1) Sport socialization processes across the body differ by gender within the same discipline.

2) The commitment of the female body in a "masculine" sport suggests the existence of specific gender socialization modes.

3) Female English boxing practitioners are confronted with a "dual constraint": mastering a "masculine" athletic gesture while demonstrating their belonging to the "woman" category.

\subsection{Study Population}

The approach adopted is of the qualitative type to access relevant data. We chose to use the semi-directive interview tool to collect information that could focus the interviewees' discourse on themes previously defined and listed in an interview guide. The subjects studied are twenty students, male and female boxing specialists from the Higher Institute of Sport and Physical Education of Gafsa (in 
the region of Gafsa, southern Tunisia). The age of these boxing practitioners ranges from 21 to 25 years old.

\subsection{Investigative Tool}

The semi-directive interview is a qualitative technique of gathering information. It allows the interviewees to focus on themes previously defined and recorded in an interview guide. The particularity of the semi-directive interview is to give more importance to the speech of the subjects. We have set up a semi-directive interview guide with the support of our questions and our readings on corporeality and socialization among athletes practicing boxing. Our choice was focused on a familiar space for students to ensure the smooth running of the interview. Each interview lasts about an hour.

The interview includes a guide organized around the following items:

1) The general characteristics

2) Body sociology

a) Bodily life

b) Body-environment relationship

c) Social interactions

d) Notional and normative acquisitions

3) Socialization

a) Sports socialization

b) Peer groups participation

c) Family configurations

\section{Discussion of the Results}

\subsection{From the Perception of the Body to Social Representations}

The body is the product of a whole social construction in its practices and its representations. In addition, sport and every other physical activity are the first field where the body is engaged. Therefore, physical and sports activities, in all their aspects, are a kind of evaluator of the body uses.

The questionnaire has shown that boxers do not all have the same body social representation. Moreover, the widespread types of the body social representations emanate from discomfort or, paradoxically; from a well-being and a self-image, the "body-well-being".

\subsubsection{The "Suffering Body"}

People often talk about their bodies when sick, suffering, or having a disability. For them, the body is a simple biological organism from which it is necessary to respond to needs (nutrition, rest, pain to heal). We will call this body first social representation the "suffering body".

English Boxing initially requires a physical effort and a disposition to endurance to pain. This is imperative if one wants to reach the top levels.

The body can reflect the person's the social malaise. "Being a female boxer, $I$ 
suffer a lot during the preparations for the fight to have a strong and a rigid body (...) Before every fight, I have to lose weight (it's a real nightmare). I became sick because of this decrease in fat mass..." (Sondes)

English boxing is one way to self-evaluate and assert and strengthen oneself against opponents through the daily attendance in the ring and the preparation to fight. One can understand from this that the body can be put to the test of the invisible sufferings and wounds which nevertheless remain the vivacious witness of the past trials.

"During my practice of boxing, I discovered what the suffering is. I suffer during the training, before the combats (diminution of the fat mass), during the combats and after the combats. The ring is a story of suffering experienced by the body when giving and receiving blows, having wounds, leaving with broken nose..." (Basma)

In the gym, the boxers put in place their fighting body techniques without much endurance and perseverance. In fact, many testimonies show fighting body wounds and daily experiences. In this context, Maurice Godelier (2009: pp. 49-50) speaks of "identities in conflict".

"(...) the blow in the hoarseness of an exhalation that instantly betrays the magnitude of my surprise. The guard remains uncertain while my steps stumble on the jolting of my breath. I try to resume the fight. With an icy look, I stay at a distance from my opponent, dodge and run away from him until my body absorbs the pain..." (Mohammed)

"I was stung with a rather violent plexus attack which interrupted the confrontation for almost a minute. To be deprived of the faculty of breathing while one is in full effort is the most unpleasant sensation. It follows a physiological defeat against which any desire to recover remains powerless... "To be hard to the pain". (Sofien)

\subsection{2. "The Body-Well-Being"}

Through all the physical activities that are dispensed to it, including diets, beauty care and other performance techniques, the body enjoys a great valorization. For their part, the media do not skimp on new methods that aim to help the body keep a good state and in top form. Thus, we witness a real emancipation of the body from all the attachments imposed by religion and morality. We can speak freely about the body as an object which deserves consideration.

In a society subject to a hierarchy, establishing body politics is inherent to the power over the body. In society, each class forges a body image that P. Bourdieu qualifies as a body hexis. For him, this image is the subjective representation of the body of the individual that is specific to each social layer. We can check it in the way of presenting oneself and showcasing oneself, in the care provided to the body, in the recommended diets, or in the physical and sports practices.

The interview analysis shows that most English boxing students (8 out of 10 students) come from disadvantaged backgrounds. Imen says, "Given the precarious material situation of my family, the practice of boxing offers me the op- 
portunity to deliver me from all the gloom of life. I let off steam, I forget all my sad reality, and I feel too strong and able to realize my dreams."

"...Integrating the practice of boxing has allowed me to become physically stronger, I feel safer in my neighborhood. Nobody can insult me. Since I believed in boxing, I gained confidence in life." (Achref)

English Boxing has two dimensions:

- An essentially individual dimension that calls for going beyond one's aptitudes and assuming one's actions.

- A relational dimension in the affront as we approach the other taking into account its physical and moral integrity.

\section{Boxing, a school of life:}

This sport is already provoking the enthusiasm of young people. It is clear that boxing inculcates republican values through openness, but it also teaches tolerance, ethical and humanistic values (courage, humility and respect for others). Boxing is a powerful tool going beyond any innate resistance in the man. It offers people another vision. Boxing also includes rites which ensure the passage to adulthood and an ability to channel an inner force that creates a way to apprehend life beyond the purely material facade. This is the time when the body of the boxer is forged more clever and harder to pain. In addition, it is important to call for a controlled commitment of participants.

Boxing is an individual sport where there is no need to rely on others. "To touch and not to be touched" means a maximum risk taking, always controlled, while respecting the opponent... In addition, boxing means acting out and questioning oneself. Moreover, boxing allows to become aware of its faults and to accept failures. This makes of consolidation of the personality an important factor.

"This sport practice has taught me the notions of respect, equality, rules essential to be respected (recognition as an individual recognized by others) and therefore to respect others. Also, the individual must know how to claim his particularity (existing for his qualities) while observing the imposed rules". (Meriem)

Whether an adequate alternative or a simple tool, boxing pushes all its virtues to bring out the young idle of his cocoon and to help a person overcome fears and doubts to regain some assurance.

However, teaching individuals developed combat techniques without raising moral awareness is very risky. In fact, by its specificities, boxing exempts an exemplary education in its penalties (reminder to the law and the rules), in the responsibilities, in the socialization which it implies (life in community, acceptance of the differences) and in the suffering and the pleasure which it can provide and which it is necessary to accept (as culmination of acceptance of one's own suffering). In short, boxing can be likened to a real school of life.

"I was too agitated and aggressive. Thanks to boxing, I learned to control my body and to channel my violence and my overflowing energy, and to respect the sporting and social rules (in the ring as in life). I also learned the overtaking and the valorization of it." (Karim) 
Therefore, the gymnasium is the place where body techniques are acquired while incorporation subjective dimensions (the sensations, expressions and self-tests that crystallize in the practice of boxing) are incorporated. In fact, this corroborates the idea of the "carnal sociology" supported by Wacquant even if it does not relate it explicitly to Crossley phenomenological conceptions of flesh (1995: pp. 45-48) when he places his reflections in the wake of Maurice Merleau-Ponty.

\subsection{Social Representations of ISSP Gafsa Students}

\subsubsection{Boxing Practice Designs}

Given the quantitative progression of women's practice and their access to "masculine" disciplines, the world of sport remains rather a recalcitrant social domain with regard to power relations that are favorable to women (Elias \& Dunning, 1994: p. 165). For many, there is no doubt that the field of sport is a real academy that does not only form manhood but also discipline and obedience. In this context, Messner, Sabo emphasize that sport promotes the incorporation of behaviors that consolidate class and gender hierarchies (Messner \& Sabo, 1990: p. 13). On the other hand Connell, R. (1995: pp. 25-27) believes that learning to be a man on sports grounds requires some physical violence, strength, skill and the expression of a latent power.

Boxers clearly demonstrate their denigration of boxing for women arguing that other "feminine" sports (gymnastics, aerobics, dance) are more appropriate to them.

"This sports practice is the best of combat sports. In the ring, I learned to be responsible, decisive, autonomous, aggressive, hard, and respectful; the practice of boxing forges the masculine personality. That's why I do not see any place for women in this practice." (Achref)

"Boxing is a hard sport designed for men. It requires a lot of strength, endurance, rigidity, and aggressiveness. I am completely against women who practice boxing. I will not accept that my wife or my sister practice boxing." (Karim)

Because it symbolizes the natural superiority of men over women, Connell, R. (1987: pp. 183-188) considers that sport is a kind of image of hegemonic masculinity. However, this is not the case for most institutions where physical strength is no longer a decisive criterion for male preeminence. In addition, the institutional organization of sport implements social gender relations in a specific way: competition and hierarchy among men, and exclusion or domination of women (Connell, 1995: pp. 25-27). Boxers are categorical; they refuse discrimination (women's sport and men's sport). Women can practice all sports just like men.

"Boxing is not a men's practice. The woman can be very successful in this sport at the international level while keeping her femininity. She is able to resist fatigue. She is enduring, strong, fast, agile, and clever..." (Sawsen)

\subsubsection{Women in a Socially Apprehended Practice as "Masculine"}

According to Theberge, N. (1995: pp. 105-116), women see in the practice of 
boxing a transgression of the widespread representations relative to the sports by engaging in the learning of corporal techniques that are historically and symbolically considered "masculine". For women this is seen as a real emancipation. Therefore, these sports are torn between the mastery of a "masculine" sports gesture and the maintenance of their membership in the category "woman" not to be subject to stigmatization processes (Laberge, 1994).

"To master the techniques of boxing, I forget that I am a woman. I forget my body and my self-esteem. My body becomes stronger. Outside of practice, I become a woman again." (Meriem)

This women antipode situation means that girls are required, from the time of their primary socialization to have sexual dispositions that will allow them to feel interested in activities that are not socially intended for them. Access to a career (Becker, 1985: pp. 278-281) of high-level boxers actually calls for a double "work of the incorporated schemes, allowing both the mastery of 'masculine' sports techniques and appropriation of feminine 'genderism'." (Secondary socialization).

"In my childhood, I enjoyed playing with boys, I loved to argue with my big brother. I was very active and aggressive. My parents were against the practice of boxing. They said this fighting sport is designed for boys. I suffered a lot to have their agreement. At first, I lied about the practice of boxing. In reality, this sport makes the woman stronger and more enduring. Boxing has no influence on femininity, I am always a woman but just with a beautiful musculature." (Sawsen)

This leads to understand that woman integration in a "masculine" sport and the craze she can bring to her calls for provisions. This would reinforce idea that there are specific modes of gender socialization within particular family configurations.

\subsection{Specific Socialization Modes}

\subsubsection{Sports Socialization and Participation in the Peer Group}

Our investigations reveal that the questioned subjects experienced early competitive sports socialization. We spoke with two boxers who were led in their choice by their father and one by his brother. Some fathers and brothers, often experienced sportsmen, more explicitly encourage girls to try many sports. The first sports practices chosen are athletics and handball remain fairly "traditional". The widespread mentality in Gafsa region is that combat sports, and especially boxing, is a "male" practice.

For the majority of female boxers, the integration in sports practice originates from peer groups, either female or male. Sportswomen participate systematically in boys' groups and games. This is somewhat different from the gender grouping patterns observed during child interactions (Maccoby, 1995: pp. 347-364). They have all established privileged relationships with cousins or friends who share a taste for outdoor physical activity.

"Since my childhood, I prefer games and the company of boys. My two cousins practice boxing. I used to accompany them in training, I was fascinated by 
this practice that gave me confidence and muscles strength." (Imen)

These female boxers generally refuse to join the girls' group and even go so far as to joke about their ways of being and about their activities. They are clearly willing to be assimilated to boys' groups and show a clear denigration for everything that is "feminine".

"I feel comfortable with boys. They are strict and responsible while the girls do nothing but cry for any reason. My father considers me responsible more than my big brother. I often help him in his bakery job." (Basma)

Combined with socialization within the male peer group, sports socialization is being consolidated to establish gendered dispositions that can be described as "inverted" or "masculine". Thus, the girls 'sporting skills make it easier for them to join the boys' group. Their activities within the male group encourage the development of their sports skills, physical strength, and demonstration of aggression.

It is important to know that individuals do not receive the same type of socialization. This depends on the group of membership. This is due initially to the fact that society is a heterogeneous institution made up of distinct social groups, each with its own culture. Some fathers, often formerly experienced sportsmen, more explicitly encourage their boys to try to practice their sport and encourage them to participate in competitive terms.

"Although I had three brothers and two sisters, I was closer to my father. He most often watched boxing matches since he was a former boxer. I started to admire this game. My father brings me to practice every day. He encourages me to be the best." (Mohamed)

Boxers all come from disadvantaged backgrounds. Each of the boxers lived a difficult life.

"I lived in a poor family in the neighborhoods without a father. The father is still important, it is a big lack. My mother could not raise us alone. She remarried. My misfortune began then, I had to work to continue my studies. To defend myself at work in the souk and in the neighborhood, I had to be a boxer. I was very influenced by my friends who practice boxing." (Achref)

"At the age of four, my father died. My big brother took his place. He was really like my father, I loved him very much. He handed me his boxing practice. In his eyes I was good. Following a fatal accident, I lost my father for the second time. It was the shock of my life, I can overcome it more. Today, I do boxing to continue to live, to be with my second father." (Sofien)

The dominant culture and body socialization o can be identified with factors of domination in, and through the body. For Brohm, JM. (2001: pp. 162-193) "Class antagonism imposes on each one a class body. The embedded idea that each class is made of the legitimate body."

\subsubsection{Special Family Configurations}

The model of the "tomboy" favors an "inverted" gender socialization already mentioned in some works on women integrating trades or "male" sectors 
(Daune-Richard \& Marry, 1990; Quemin, 1998: pp. 100-111). We often find this situation in exclusively female siblings. One of the girls in the family, often the youngest, assumes the role of the tomboy and integrates a "masculine" sport. It is a way to fill the disappointed but strongly expressed expectations of fathers to have male offspring. The girls in the Gafsa region never say that they are "tomboys". They rather say: "I am responsible, strict, and autonomous".

"I am too attached to my father who is a farmer. I accompany him in his work at the market ... I do not have a brother, so I help him in his work. I love my father's and the boys' company since my early age. I am responsible, strict and autonomous more than my sisters. I hate girl' games. Combat sports make the person stronger physically and morally." (Meriem)

In the region of Gafsa, there are popular neighborhoods with very close houses. "Elhamila (Awled Slema)" is our example. Girl socialization can be entrusted to her cousins and her relatives. In this case, girls follow their loved ones in their games and on men's sports fields. Once again, impregnated practice learning does not emanate from a conscious choice of family members but from a diffuse and sometimes hidden learning process.

\subsubsection{The Notion of "Sexed Dispositions"}

All levels of total or partial adherence to the "tomboy" identification model are related to the degree of coherence between modes of sexual socialization and the more or less pronounced precocity of sports socialization. It is certain that sportswomen who have not undergone the annotations of the model of the "tomboy" have been the object of an early and constant control of their sexual identity. Therefore, it appears that family socialization runs counter to that of the male peer group. Integrating in a "masculine" sport practice does not prevent the boxers from being subject to family control.

"Boxing promotes the muscles development. At times my way of walking has changed. My parents and my older sister have made the remark'. (Imen)

To sum up, the interviews analysis revealed that the body social representations of the boxers are not unanimous. In fact, there are two types of body social representations emanating either from the malaise (the image of the "suffering body") or from the experienced well-being and the aroused satisfaction (the image of the "body-well-be").

In addition, the field of sport is a place of learning manliness but also discipline and obedience. It is the place for the incorporation of behaviors that reinforce the hierarchies of class and sex (Messner \& Sabo, 1990: p. 13).

The respondents experienced early competitive sports socialization. We were able to talk with two boxers guided by their fathers and one by his brother. Some fathers and brothers, often experienced sportsmen, more explicitly encourage girls to try many sports especially "traditional" are athletics and handball. Given the specificity of the Gafsa region, the majority considers that combat sports and especially boxing is a "masculine" practice. For many boxers, the choice of the sporting practice comes from the groups of peers being feminine or masculine. 
Sportswomen participate systematically in the group and in the boys' games. Thus, they distinguish themselves from the modes of grouping by sex observed during the infantile interactions (Maccoby, 1995: pp. 347-364). They have all established privileged relationships with cousins or friends who share a taste for outdoor physical activity. However, it should be noted that sportswomen least concerned by the "tomboy" model have not made the exception within their family for an early and constant control of their gender identity. In reality, family socialization differs from that of the male peer group and despite the practice of a so-called "male" activity, boxers are under family control.

\section{Conclusion}

From a corpus of interviews with practitioners of boxing, we tried to highlight corporeality and socialization among athletes. This research essentially touches the perspective of the sociology of the body in relation to the modalities of highlighting corporeality and socialization by the sports institution.

Regarding the first hypothesis: the processes of sport socialization across the body differ according to sex within the same discipline; the analysis of the interviews shows that this hypothesis is confirmed. For boxing, the socializations differ according to their group of membership. Thus, society is a heterogeneous whole integrating distinct social groups, each having its own culture. Some fathers, often formerly experienced sportsmen, more explicitly encourage their boys to try to practice their sport and encourage them to engage in competitive conditions. The boxers are all from disadvantaged backgrounds. The testimonies overlap in life very difficult materially and psychologically. Their entry into boxing was assured by parents, peer groups but also through the media through the great boxers videos.

The subjects surveyed emphasize having lived an early competitive sports socialization. Some fathers and brothers, often experienced sportsmen, more explicitly encourage girls to try many sports, but the first sports practices chosen are generally quite "traditional" (athletics, handball...). In addition, Surveys have also shown that the majority of female boxers have been significantly influenced in the choice of their sport by female or male peer groups. Sportswomen participate systematically in the group and games of boys, and deviate from the modes of grouping by sex observed during child interactions (Maccoby, 1995: pp. 347-364). They have all established privileged relationships with cousins or friends who share a taste for outdoor physical activity. It should also be noted that the interest of women in boxing comes mainly from the fact that women practitioners go beyond the dominant representations of women sportswomen and choose to integrate in the learning of body techniques historically and symbolically considered "masculine" (Theberge, 1995: pp. 105-116).

For boxers, the passion of boxing is transmitted through family socialization, particularly by the father or by their enthusiasm for this activity. Also, boxing practitioners have a certain inclination to show their physical potential and to 
assert themselves before peers in their social environment.

The field of sport is a fertile ground for the inculcation of virility but also of discipline and obedience, "it favors the incorporation of behaviors that reinforce the hierarchies of class and sex" (Messner \& Sabo, 1990: p. 13). Involving a proven masculinity on sports grounds implies being able to be physically violent and to show strength and skill, an expression of latent power (Connell, 1995: pp. 25-27).

In order to complete our study, we analyzed the second hypothesis: the commitment of the female body in a "masculine" sport suggests the existence of specific modes of gendered socialization. It is through the analysis of student interviews that we were able to confirm that the determinants of socialization are related to the type and nature of physical activity. On the other hand, the analysis of the interviews of boxing reveals the "martyr" side of the body. Indeed, the study of the interviews clearly showed that the social representations of the body, for boxers, did not respond to a single model. In addition, two types of social representations of the body coexist, highlighting either discomfort, the "suffering body", or well-being and self-image, the "body-well-being". Admittedly, boxing actually requires physical effort and a disposition to endurance and pain, which are undoubtedly prerequisites for winning on the front of the sports scene. Indeed, the body is often perceived as the place where the social malaise experienced by each individual is expressed.

Boxing is a school of life. Undeniably, the activity in itself arouses a certain attachment for young people. Boxing seems to be a bridge allowing a clear republican integration thanks to the openness and the notion of tolerance that it develops and teaches. The values it conveys are courage, humility and respect. It is a powerful tool that can transcend the person, show him or her another way, a tool that presents rites of passage into adulthood, a way to channel a bubbling inner force, a way of seeing life beyond of purely material facade. This is the moment when the body of the pugilist is forged, becomes more skillful, harder for evil. This requires a controlled but total commitment by the participants.

Finally, we analyzed the third hypothesis: Boxing practitioners are confronted with a "dual constraint": mastering a "masculine" sporting gesture, while demonstrating their belonging to the "woman" category. It is therefore clear that these sports are in a dilemma where they must demonstrate a mastery of a "masculine" sports gesture and constantly demonstrate their belonging to the "woman" category, in order to avoid stigmatization processes (Laberge, 1994: pp. 51-64). In addition, the model of the "tomboy" favors an "inverted" gender socialization as treated in some studies on women who have chosen to integrate trades or "male" sectors (Daune-Richard \& Marry, 1990; Quemin, 1998: pp. 100-111). In fact, sportswomen less marked by the model of the "tomboy" have certainly been the object, within their family, of an early and constant control of their sexual identity. This shows that family socialization goes against that of the male peer group and knowing that boxing is a so-called "male" activity, boxers 
remain under family control.

For women involved in this practice of boxing, it is a form of transgression representations, mainly machismo, dominant female sports, even a kind of emancipation by commitment to the learning of body techniques historically and symbolically "masculine" (Theberge, 1995: pp. 105-116). This does not negate the fact that these sports are caught between two expectations: to master a "masculine" sports gesture and maintain their membership in the category "woman".

\section{Conflicts of Interest}

The authors declare no conflicts of interest regarding the publication of this paper.

\section{References}

Arnaud, P. (1996). Gender or Sex? Female Sport and Social Change (XIXth Century). In P. Arnaud, \& T. Terret (Eds.), History of Women's Sport. Men's Sport-Women's Sport: Education and Society (pp. 147-183). Paris: L'Harmattan.

Becker, G. S. (1985). Human Capital, Effort, and the Sexual Division of Labor. Journal of Labor Economics, 3, S33-S58. https://doi.org/10.1086/298075

Berthelot, J. M. (1983). Corps and Societies. International Cahiers of Sociology, 74, 119-132.

Berthelot, J. M. (1992). The Body as a Discursive Operator or the Aperies of a Sociology of the Body. Sociologies et societies, 1, 11-19. https://doi.org/10.7202/001061 ar

Brohm, J. M. (2001). The Analyzer Body. Essays of Critical Sociology. Paris: Anthropos.

Bryson, L. (1990). Challenges to Male Hegemony in Sport. In M. Messner, \& D. Sabo (Eds.), Sport, Men and the Gender Order: Critical Feminist Perspectives (pp. 173-184). Champaign, IL: Human Kinetics.

Butler, J. (2006). Troubles in the Genre. Feminism and the Subversion of Identity. Paris: Discovery.

Connell, R. (1987). Gender and Power: Society, the Person and Sexual Politics. London: Polity.

Connell, R. (1995). Masculinities. Berkeley, CA: University of California Press.

Crossley, N. (1995). Merleau-Ponty, the Elusive Body and Carnal Sociology. Body and Society, 1, 43-63. https://doi.org/10.1177/1357034X95001001004

Daune-Richard, A. M., \& Marry, C. (1990). Other Stories of Defectors? The Case of Young Girls Enrolled in "Male" Courses in BTS and Industrial DUT. Employment Training, 29, 35-50. https://doi.org/10.3406/forem.1990.1371

Détrez, C. (2002). The Social Construction of the Body. Paris: Editions of the Threshold.

Devereux, G. (1998). From Anxiety to Method in the Behavioral Sciences. Paris: Aubier.

Elias, N., \& Dunning, E. (1994). Sport and Civilization. Controlled Violence. In Quest for Excitement, Sport and Leisure in the Civilizing Process (p. 392). London: Basil Blackwell Ltd.

Godelier, M. (2009). Community, Society, Culture: Three Keys to Understanding Identities in Conflict CNRS (pp. 60).

Henry, M. (2001). Philosophy and Phenomenology of the Body. Paris: PUF. 
Héritier, F. (1996). Masculin, Female. The Thought of Difference. Paris: Odile Jacob.

Laberge, S. (1994). For a Convergence of the Feminist Approach and the Conceptual Model of Bourdieu. STAPS, 35, 51-64.

Lachheb, M. (2008a). A Woman's Body in a Man's Sport. A Look at the Corporal Experience of Tunisian Judokas. Feminist Research, 21, 57-74.

https://doi.org/10.7202/029441ar

Lachheb, M. (2008b). The Ideal Type of Body in the Teaching of Contemporary Tunisian Physical Education. De Boeck Superior: Education and Societies, 2, 145-159. https://doi.org/10.3917/es.022.0145

Lachheb, M. (2013). Becoming a Footballer in Tunisia: Socialization and Construction of So-Called Masculine Attributes. African Studies Papers, 53, 445-463.

Le Breton, D. (1992). The Sociology of the Body. Paris: PUF.

Maccoby, E. (1995). The Two Sexes and Their Social Systems. In P. Moen, G. H. Elder Jr., \& K. Lüscher (Eds.), Examining Lives in Context: Perspectives on the Ecology of Human Development (pp. 347-364). Washington DC: American Psychological Association. https://doi.org/10.1037/10176-009

Mennesson, C. (2005). Being a Woman in the World of Men. Sports Socialization and Gender Construction. Paris: L'Harmattan.

Merleau-Ponty, M. (1996). Phenomenology of Perception. Paris: Gallimard.

Messner, M., \& Sabo, D. (1990). Sport, Men and the Gender Order: Critical Feminist Perspectives. Champaign, IL: Human Kinetics.

Quemin, A. (1998). Feminine Modalities of Entry and Insertion into an Elite Profession: The Case of Women Commissioners priseurs. Sociétés Contemporaines, 29, 87-106. https://doi.org/10.3406/socco.1998.1843

Theberge, N. (1995). Sport, Physical Characteristics and Sexual Differentiation. Sociology and Societies, 27, 105-116.

Wesely, J. (2001). Negotiating Gender: Bodybuilding and the Natural/Unnatural Continuum. Sociology of Sport Journal, 18, 162-180. https://doi.org/10.1123/ssj.18.2.162 